\title{
Study of the features of the development of computer-aided design of functional coatings by plasma spraying
}

\author{
Grigory I. Trifonov*, Lyubov A. Kukarskikh, Vladimir K. Kiryanov, Dmitry O. Krikunov, \\ and Andrey $V$. Mikhalchenko \\ Military Educational Scientific Center Air Force «Air Force academy name of Professor N.E. \\ Zhukovsky and Y.A. Gagarin», 394064 St. Old Bolsheviks 54 «A», Voronezh, Russia
}

\begin{abstract}
To date, there are a number of tasks and problem areas related to the technological preparation of plasma spraying and design of technical systems, the solution of which is most relevant in production areas. In this paper, studies of the processes occurring during plasma spraying were carried out. The analysis of the factors of plasma deposition influencing the development of computer-aided design (CAD) was carried out. In the course of research, a generalized block diagram of the CAD coating was developed. The stages of CAD formation for plasma spraying are simulated.
\end{abstract}

\section{Introduction}

Nowadays, vehicle part additive reparation methods are actively used in modern industry, particularly by machinery and aviation manufacturers. Part reparation is economically beneficial since around half of mechanisms sent to reparation can be fixed and reused at a cost of $15-30 \%$ of a new part price. Worth to notice, only 5 to $9 \%$ of parts can't be restored. [1-3].

Plasma deposition is one of the perspective methods to repair worn out parts (Fig. 1). This method allows a variation of deposited material composition: metals, cermets, ceramics can be used [2]. Other deposition methods restrict a choice of available materials [3].

At plasma deposition planning stage, technical challenges associated with a particular part and its functional coating are addressed. Particularly, there is a need for a numerical simulation of a plasma deposition process.

The goal of this work is to analyze plasma deposition process factors influencing a development of computer-aided design for thin film deposition. CAD structural scheme is being developed and studied.

\footnotetext{
* Corresponding author: trifonov gi@mail.ru
} 

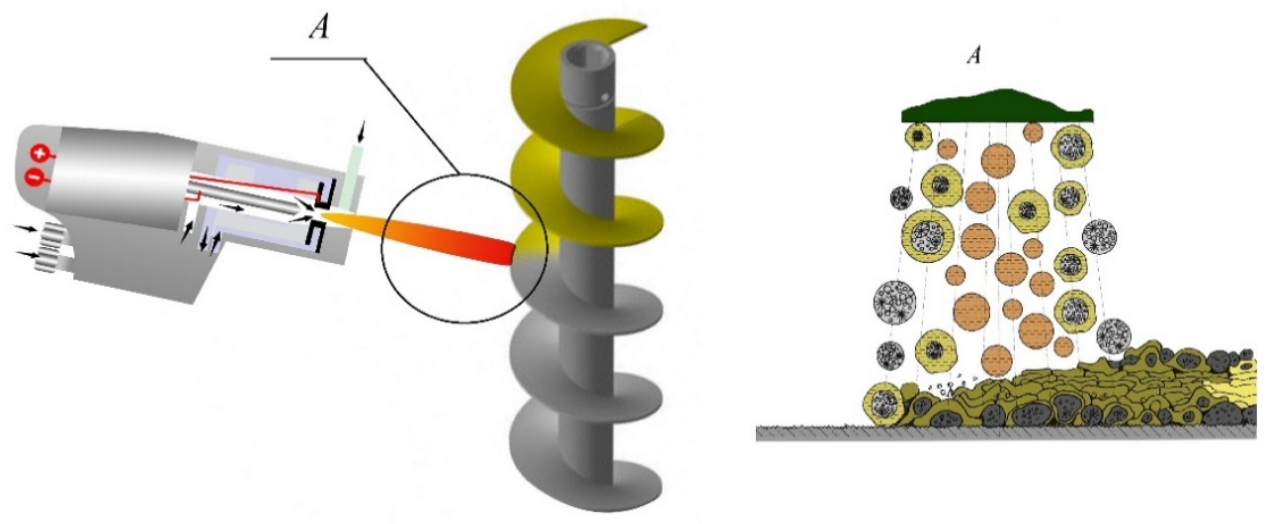

Fig. 1. Plasma deposition process.

\section{Theory}

Nowadays, datacenter computing capabilities allow using numerical simulations as a main tool in technical problem solving [4].

Considering current maturity level of plasma deposition methods, there are certain technological problems concerning their application in industry. Hence, as manufacturing equipment and technological processes are improving, it is necessary to solve a complex problem of designing CAD for plasma deposition.

However, for plasma deposition CAD it is impossible to cover all criteria and tasks available for typical CADs, due to complexity of this gas-thermal process. It possesses lots of factors and special phenomena, which can not be fully taken into account during automated design.

By analyzing plasma deposition process features [5], we highlight the main factors influencing a development of automated plasma deposition design system. These features make CAD application for discussed area quite difficult:

1) Technological process route is quite determined, as shown practically [6]. At the same time, technological process can vary in complexity, depending on requirements of a functional coating. For example, increase or decrease in a number of plasma gun roundtrips, introduction of additional surface treatment steps, etc.

2) A clean part surface and exact timing for each process step are required for plasma deposition treatment. Following these requirements, for CAD one should consider a use of special transporting and handling equipment between operations (manipulators, automated conveyors, etc.) for each particular case.

3) It is necessary to consider a part surface pre-treatment in majority of cases before plasma deposition, because surface quality check is a must to assess if part reparation process is feasible.

4) Part pre-treatment operations, as well as post-treatment processes require some special equipment which is not always considered when planning automated plasma deposition process. So, it is reasonable to combine all equipment into automated plasma deposition restoration process lines [7]. It is required to coordinate such automated line with other manufacturing services.

5) One should consider that deposition of numerous films with controlled geometry requires a precise mathematical analysis and numerical simulations based on process kinematics. As a result, different tool or process conditions are needed to implement 
different kinematic regimes of plasma deposition. This will increase a number of tasks to design a technological process route. Examples of variations in part surface are shown in fig. 2 .

6) Apart from main and support hardware for plasma deposition, there is a need for a film precursor preparation lab (as a rule, this is a composite powder), deposited film characterization lab (measuring cohesion, adhesion, residual stresses, etc.), lab for coatings field tests, etc.

7) Creating deposited film material database: possible combinations considering process temperatures and chemical interactions, substrate material properties and its interactions with deposited films, kinematic deposition regimes, etc.
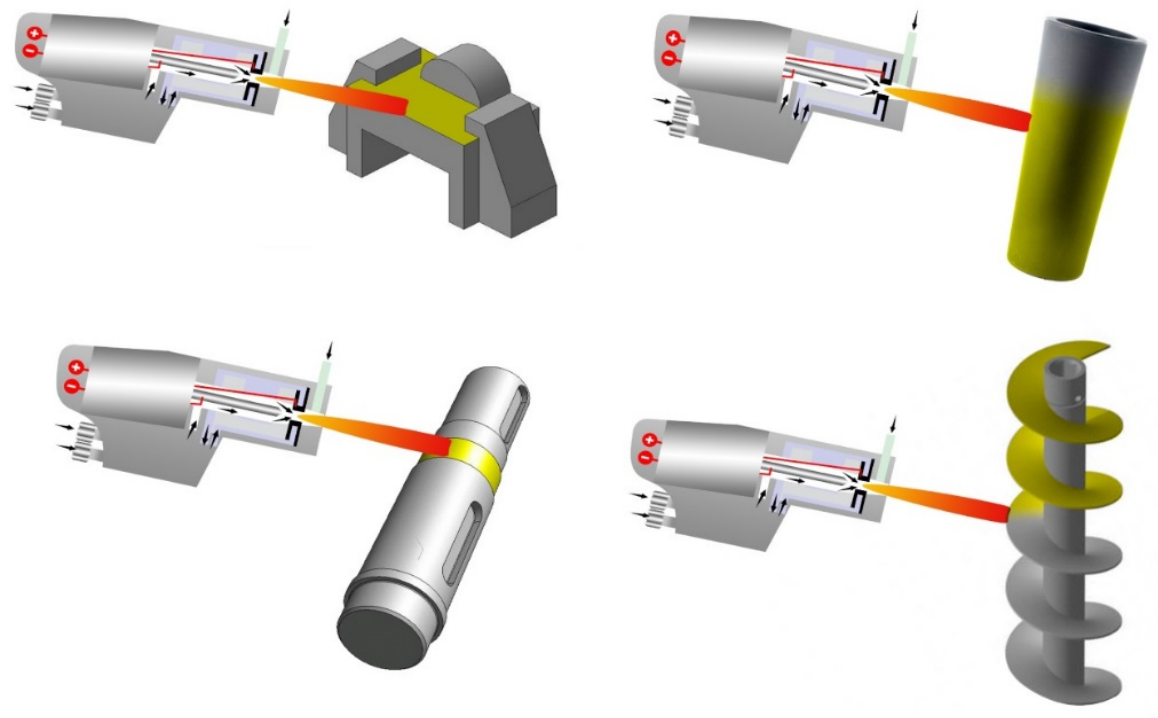

Fig. 2. Plasma deposition on typical vehicle parts.

Considering above mentioned factors and features influencing a development of automated design system, CAD development should start with creating a system of automated process modules. This conclusion is based on a fact that modern manufacturing facilities must avoid harmful work conditions; and need to increase a coating quality by treatment process automation.

\section{Research}

The main CAD goals in plasma deposition reparation facilities are the following: throughput increase; increase of facility automation level; increase of intellectual activity among technologists and design engineers; etc. Solution of mentioned tasks leads to an investigation of new technological and design ideas that will increase a coating quality and decrease process time and costs.

Therefore, a development of automated process design for functional coatings has the following stages:

1) technical task (TT) analysis;

2) search for analogues and prototypes, also existing solutions;

3) choice of material to deposit depending on requested cost and coating functionality. 
The following works are done during plasma deposition functional design stage:

choice of film material (if film properties do not meet requirements mentioned in TT, a new composite material with matching properties is developed) $[8,9]$;

choice of deposition process conditions;

technical and technological manufacturing preparations;

choice of required equipment.

If desired technological process is not available with existing equipment, a new tool or technological solution is developed.

Based on analysis of plasma deposition technology and factors influencing it, a structural plasma deposition CAD scheme was developed (Fig. 3).

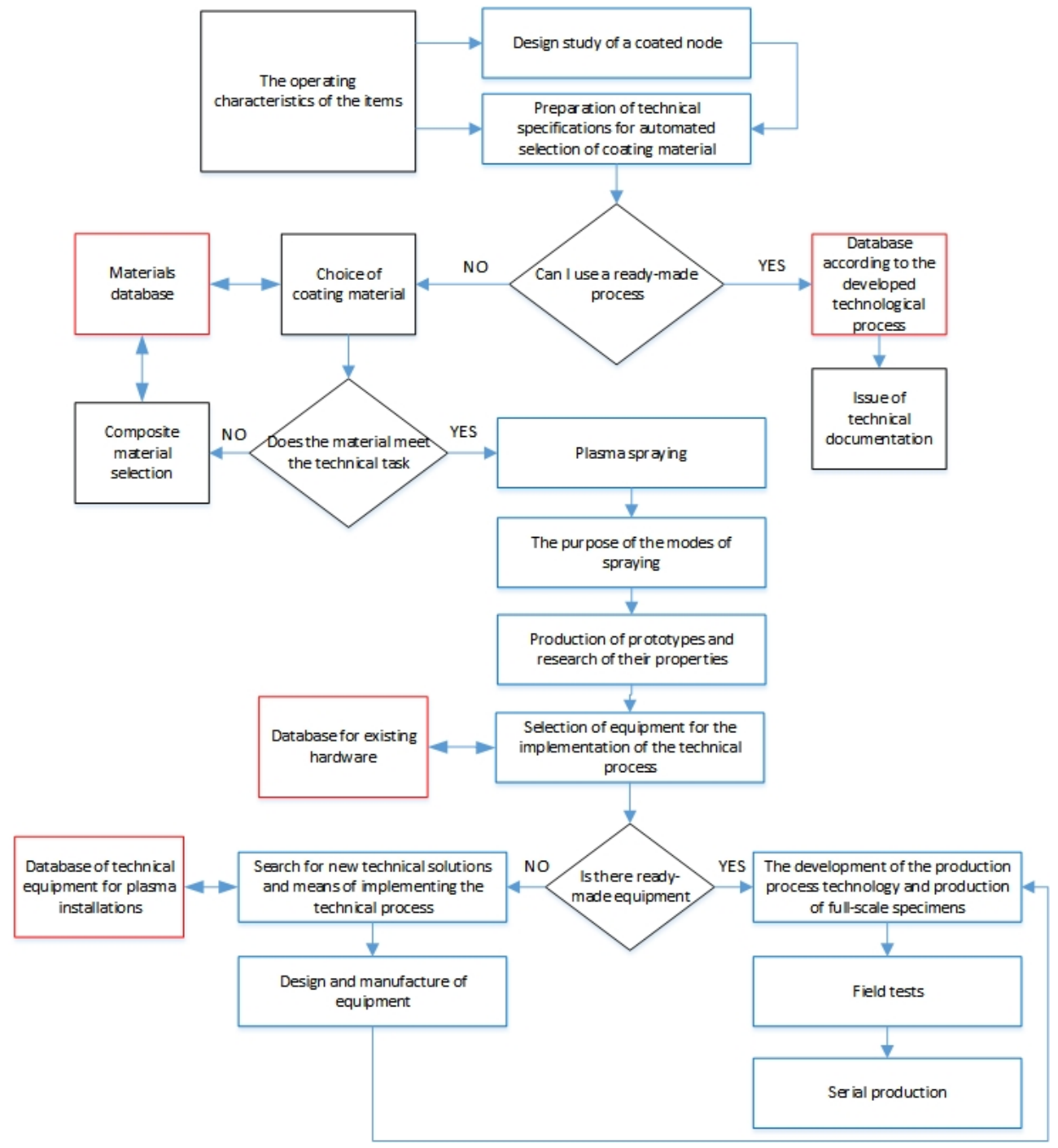

Fig. 3. A structural scheme of plasma deposition CAD.

It is worth nothing that there databases, developed during the design of the structure of the plasma deposition CAD scheme, are under the automated control of the control system (Fig. 4). 


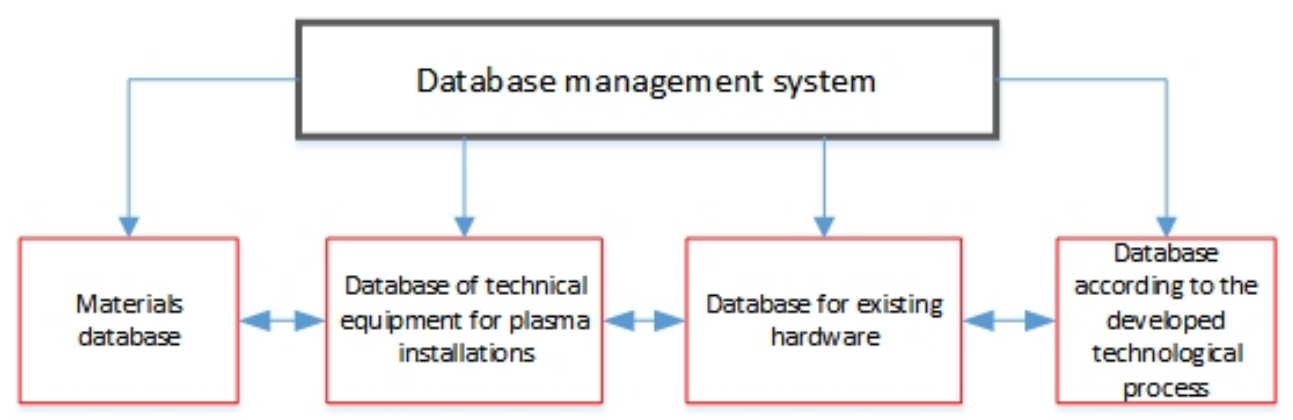

Fig. 4. The scheme of database management.

Considering developed plasma deposition CAD structural scheme, a plasma deposition process (preparation works and automated system design) can be divided into three stages.

The first stage. Basic plasma deposition process preparations are done. Parts to be coated are chosen, deposition parameters and regimes are chosen, coating parameters are analyzed and defined. Deposition complexity is estimated. A technological route (part treatment technological process) is defined, involved equipment workload is assessed.

The second stage. A send-ahead part is chosen which design and technologic properties should be as close as possible to parts described in TT. At this step process applicability is defined.

The third stage. A flexible automated system model is created, deposition process is numerically simulated. A flexible automated system working prototype is a result of this stage.

Above mentioned stages and discussed tasks can be utilized as a base for plasma deposition CAD generation. However, discussed tasks concerning part plasma deposition restoration using fully operational CAD are not fully addressed at Russian Federation manufacturing facilities at the current moment [10].

\section{Conclusions}

We made an analysis of main factors influencing plasma deposition CAD development. A generalized plasma deposition CAD structural scheme is demonstrated. Three stages of plasma deposition CAD development are composed.

\section{References}

1. A.E. Balanovsky, Plasma surface hardening of metal (ISTU publishing house, 2006)

2. L.K. Leshchinsky, S.S. Samotokin, I.I. Pirch, V.I. Komar, Plasma surface hardening (K.: Tehnika, 1990

3. A.F. Ilyushchenko, A.I. Shevtsov, V.A. Okovity, G.F. Gromyko, Processes of formation of gas-thermal coatings and their modeling (Minsk: Belarus. Navuka, 2011)

4. S.Yu. Zhachkin, G.I. Trifonov, M.N. Krasnova, N.A. Penkov, Modeling the kinematics of the plasma spraying on the figurine surface, Proceedings of GOSNITI, v. 128, pp. 133-139 (2017)

5. A.F. Puzryakov, Theoretical bases of technology of plasma spraying, (M.: MGTU name of N.E. Bauman, 2008)

6. I.N. Kravchenko, A.F. Puzryakov, V.M. Korneev [et al.], Technological processes in the technical service of machinery and equipment, (Moscow: INFRA-M, 2017)

7. G.I. Trifonov, S.Yu. Zhachkin, M.N. Krasnova, Automation of computational modules to 
estimate the parameters of plasma spraying, Innovative technologies and equipment of machine-building complex. Interuniversity collection of scientific papers, vol. 19, pp 34$40(2018)$

8. S.Yu. Zhachkin, G.I. Trifonov, S.V. Nelysov, Mathematical modeling of the deposition of composite coatings by plasma spraying, Virtual modeling, prototyping and industrial design: proceedings of the IV International scientific and practical conference. Tambov: TSTU publishing House, vol. 4, pp. 63-69 (2017)

9. S.Yu. Zhachkin, G.I. Trifonov, N.A. Penkov, Modeling the process of deposition of composite coatings based on chromium, Virtual modeling, prototyping and industrial design: proceedings of the IV International scientific and practical conference. Tambov: TSTU publishing House, vol. 4, pp. 59-63 (2017)

10. G.I. Trifonov, Features of modeling parameters of plasma deposition for parts of aircraft, International scientific and practical journal «Engineering solutions and innovations» vol. 1(10), pp. 31-40 (2018) 